\title{
Analysis of an intramedullary nail to treat tibia fractures
}

\begin{abstract}
Throughout the history of man, he has sought to make his body function optimally, even though the functioning of it deteriorates over time either, by disease or by accident. This need for healthy well-being has led to the research of various materials with which it is possible to make permanent or temporary replacements within the body, without altering the physiology of the human being. Malformations or fractures of the lower limbs (tibia) in the human body are the common, so has sought ways of treating such diseases. Fortunately, thanks to scientific and technological advances, since the end of the 19th century, with the development of aseptic surgical techniques and from1940 with research different metals and alloys, technological development in the surgical field haven been approached and propositae its use on prostheses or stents.
\end{abstract}

Keywords: fractures, surgical and malformations, physiology, surgical techniques
Volume 3 Issue 5 - 2019

\author{
Islas Jiménez DI,Avalos Flores JC, Romero \\ Ángeles B, Urriolagoitia Sosa G, Espinosa \\ Hernández ME, Martínez Reyes J,Vazquez \\ Feijoo JA, Urriolagoitia Calderón GM \\ Instituto Politécnico Nacional, México
}

Correspondence: Islas Jiménez Diego Ivan, Instituto Politécnico Nacional, Higher School of Mechanical and Electrical Engineering, Lindavista, CP. 07320, Mexico, Email Islas-jimenez_17@hotmail.com

Received: October 15, 2019 | Published: October 30, 2019

\section{Introduction}

The clinical success of a metallic implant depends on the process of osteointegration, which is subject on one hand to the mechanical biocompatibility with the bone it replaces, this is achieved by means of proper mechanical materials capacity that allows the material to withstand aggressive environment that mainly exist within the human body, among others it can be mention as materials characteristics low elastic module, high resistance to breakage, wear, fatigue and corrosion and, other factors such as its macroscopic and dimensional design, material and surface topography of the implant. ${ }^{1}$ The manufacture of implants should be done with materials that, when remaining inside the human body and in contact with living tissues and physiological fluids, remain inert to the body, this is in order not to generate a rejection or some negative effect. These materials are called biomaterials. The main characteristics that biomaterials must fulfill with their function are: Biocompatibility. It is the capacity of the material, which when placed within the human body does not activate the defense lines of the organism, therefore, there is no rejection. Bioactivity ability to stimulate or cause a biological reaction in the receiving tissue thus favoring its integration. Bioinercia material's ability to cause no reaction in surrounding tissues. One of the most commonly used materials for stents or prostheses, is Titanium and its alloys thanks to the mechanical properties they offer, which depend on their degree of purity. Basically, Titanium is characterized by its lightness, high resistance, low module of elasticity, low thermal expansion and biocompatibility. High purity Titanium and Titanium $\mathrm{cp}$ are (commercially pure) on the market in four grades (grade 1 to 4 ).

\section{Methodology}

The new computational methods of reconstruction of bones in a three-dimensional way have become a very important tool for the branch of medicine. However, in order to obtain these models, it is necessary to follow consecutively a series of steps using computational tools that allow, in addition to generate reconstruction, simulate the behavior that it would have under certain working conditions. Using the Scan IP ${ }^{\circledR}$ program, cloud of points is exported from the digital file obtained from a computerized axial tomography of the tibia, and then reconstruct a where solid from meshes generated with a Power Shape ${ }^{\circledR}$ program. Once the solid bone model is obtained, it is used a Solid Works ${ }^{\circledR}$ mechanical design program, in which the bone is assembled with the nail as seen in Figure 1, resulting in a bone-nail system to be submitted to an analysis through the Finite Element Method (FEM).



Figure I Bone-nail system under numerical study conditions. 
To this bone-nail system, a numerical simulation is applied through the ANSYS® computer program, academic version 18.13. To carry out this study, a structural analysis is considered where a highorder element (Solid brick 186, 20 nodes and 6 degrees of freedom) is used, this type of element has proved to be the most convenient to be applied to three-dimensional pieces or objects. The size of the discretized model has thin elements smaller than $1 \mathrm{~mm}$, resulting in 54,875 nodes and 26,651 elements from the whole bone system. A linear-elastic analysis is considered, with a Modulus of Elasticity 104 GPa and Poisson's ratio of 0.33 . The loading external agent depends on the position of the foot, for this study it was carried out considering a total anchorage of movements at the tibial plateau of the bone and in the interior malleolus a force of $25 \mathrm{~kg}$ is applied.

Finally, with the development of the analysis it can be observed the mechanical behavior that presents the nail within the system, under compression conditions. In the Figures $2 \& 3$ it is possible to see the maximum stress generated, as well as the maximum elongation of the bone-nail system. ${ }^{2,3}$

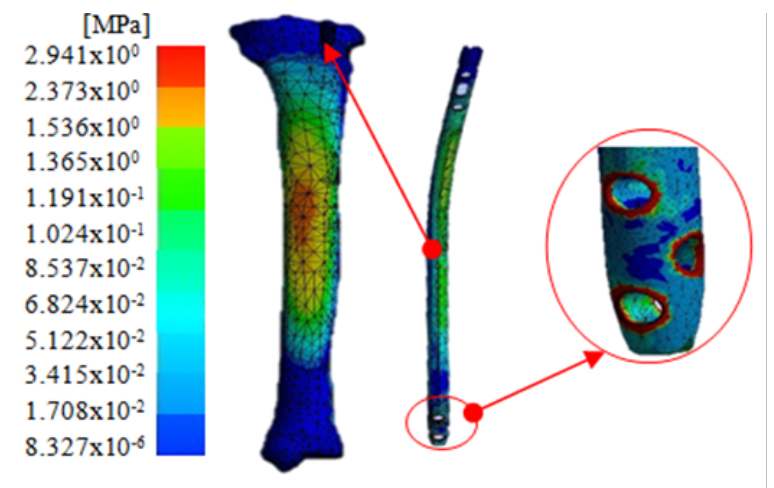

Figure 2 Graphical representation of the color map showing the maximum stress generated in the bone-nail system.

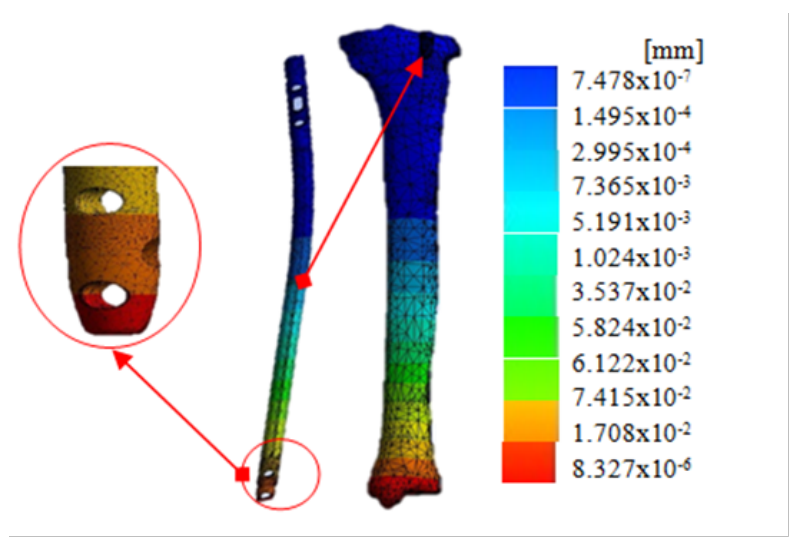

Figure 3 Graphical representation of the color map showing the displacement generated in the bone-nail system.

\section{Conclusion}

With reference to the results obtained, it was observed that the total elongation suffered by the intramedullary nail is of the order of micro elongations, by which the functioning of this will not be affected the entire system. In the numerical simulation conditions the bone-nail system is working below the elastic limit of both materials (Titanium $6 \mathrm{AL}-4 \mathrm{~V}$ and bone), that is, within the elastic linear zone, guaranteeing that there will be no permanent deformations or stresses that could cause to system failure. This research leaves the precedent for further studies to evaluate the behavior for different cases of fractures that the tibia may present and thus seek improvement in the design or materials of the intramedullary nail, depending on the shape and severity of the injury being treated. In addition to allowing to evaluate the load conditions for the implemented therapies that promote a correct physical rehabilitation of the patient, seeking the reduction of recovery time. It is important to note that the results obtained in the numerical and analytical analyses of the design proposed in this research show that the mechanical properties of the intramedullary nail are ideal for the required work, so it is contemplated that the manufacturing of the nail will have a positive impact in terms of costs and improvement of treatments.

\section{Acknowledgments}

The authors thank the Instituto Politécnico Nacional and the Consejo Nacional de Ciencia y Tecnología for the support provided to develop this research.

\section{Conflict of interest}

Authors declare that there is no conflict of interest.

\section{Funding details}

None.

\section{References}

1. Lario Femenía J, Amigó Mata A, Vicente Escuder A, et al. Development of Titanium alloys and surface treatments to increase implants life. Journal of Metallurgy. 2016;52:1-13.

2. Navarrete Lopez LM. Materials for internal prostheses. Materials for Engineering. 2015. p. 1-8.

3. ANSYS Mechanical APDL Basic Analysis Guide Relay 18.1, ANSYS Inc Company. 2017. 